\title{
The sociology of creativity: Part I: Theory: The social mechanisms of innovation and creative developments in selectivity environments
}

\author{
Tom R. Burns ${ }^{\mathrm{a}, \mathrm{b}, *}$, Nora Machado ${ }^{\mathrm{b}}$ and Ugo Corte ${ }^{\mathrm{a}}$ \\ ${ }^{a}$ Department of Sociology, University of Uppsala, Uppsala, Sweden \\ ${ }^{\mathrm{b}}$ Lisbon University Institute-CIES, Lisbon, Portugal
}

\begin{abstract}
Creativity is a universal activity, essential in an evolutionary perspective, to adaptation and sustainability. This first part of a three part article on the sociology of creativity has three purposes: (1) to develop the argument that key factors in creative activity are socially based and developed; hence, sociology can contribute significantly to understanding and explaining human creativity; (2) to present a sociological systems approach which enables us to link in a systematic and coherent way the disparate social factors and mechanisms that are involved in creative activity and to describe and explain creativity; and (3) to illustrate a sociological systems theory's conceptualization of multiple interrelated institutional, cultural, and interaction factors and their role in creativity and innovative development in diverse empirical instances.

The article introduces and applies a model stressing the social embeddedness of innovative agents and entrepreneurs, either as individuals or groups, as they manipulate symbols, rules, technologies, and materials that are socially derived and developed. Their motivation for doing what they do derives in part from their social roles and positions, in part in response to the incentives and opportunities - many socially constructed - shaping their interaction situations and domains. Their capabilities including their social powers derive from the culturally and institutional frameworks in which they are embedded. In carrying out their actions, agents mobilize resources including technologies through the institutions and networks in which they participate. Following this theoretical part, Parts II and III focus on the concrete conditions and mechanisms characteristic of the "context of innovation" and the "context of receptivity and institutionalization", respectively.
\end{abstract}

Keywords: Creativity, innovative development, system theories, sociology, psychology, agency, rule regime, creativity production function, context of creativity, context of receptivity and selectivity

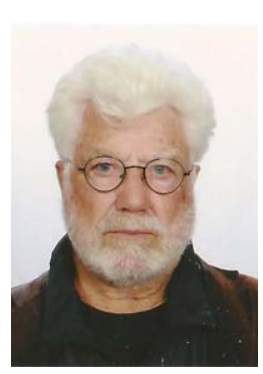

Tom R. Burns (Professor Emeritus of Sociology at Uppsala University, Sweden and Research Associate of the Lisbon University Institute (ISCTE), Portugal) has published internationally more than 15 books and 150 articles in substantive areas of governance and politics, environment and technology, administration and policymaking; also he has contributed to institutional theory, sociological game theory, theories of socio-cultural evolution and social systems. He has been a Visiting Scholar, Stanford University (2004-2013), Jean Monnet Visiting Professor, European University Institute, Florence (2002), Fellow at the Swedish Collegium for Advanced Study

*Corresponding author: Tom R. Burns, Department of Sociology, University of Uppsala, Uppsala, Sweden. Tel.: +46 7082 47050; E-mail: tomnora.burns@gmail.com.
(1992, 1998) and at the Wissenschaftszentrum Berlin (1985) and a visiting professor at a number of leading universities in Europe and the USA.

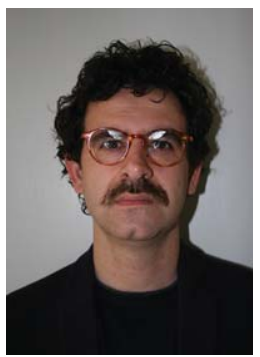

Ugo Corte Post-Doc in Sociology, Uppsala University, Sweden, conducting research on small groups, social movements, innovation, and governance. His research on democratic governance with Tom R. Burns has been published by Giulio Einaudi Press, and his work on social movements with Bob Edwards has been featured in Music and Arts in Action (MAiA), and in Sport in Society. His latest work on small groups dynamics and creative processes has been featured in the Social Psychology Quarterly (SPQ) (2013). His dissertation (2012) (in Sociology, Uppsala University) is titled Subcultures and Small Groups: A Social Movement Theory Approach and uses and theorizes the advantages of employing social movement theory to

ISSN 0167-2533/15/\$35.00 @ 2015 - IOS Press and the authors. All rights reserved

This article is published online with Open Access and distributed under the terms of the Creative Commons Attribution Non-Commercial License. 
analyze the emergence, activities, and development of subcultures and small groups.

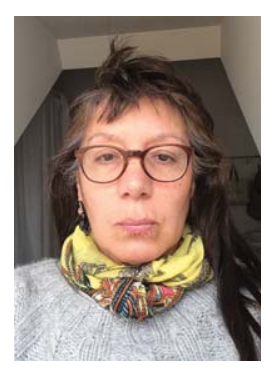

Nora I. Machado des Johansson is a researcher associated with the Center for Research and Studies in Sociology CIES, at the Lisbon University Institute (ISCTE), and to the Department of Sociology, University of Gothenburg in Sweden. Machado's main areas of research are sociology of culture, social cognition and organization. Her studies also concern the sociology of ethics. Among her publications are articles in Public Administration: An International Quarterly, Canadian Journal of Sociology, Social Science and Medicine, Death Studies, Human Systems Management and a book Using the Bodies of the Dead: Legal, Ethical and Organizational Dimensions of Organ Transplantation. Ashgate Publishers, England 1998. She is now currently completing a book about normative and cultural changes in end-of-life decisioin-making.

\section{Background ${ }^{1}$}

This work has three purposes: (1) to argue that key factors in creative activity are socially based and developed; this implies that sociology can contribute to understanding and explaining human creativity; (2) to apply sociological systems theory, in particular, ActorSystems-Dynamics (ASD), in conceptualizing multiple interrelated institutional, cultural, and interaction factors and mechanisms in describing and explaining creativity; ${ }^{2}$ (3) to enable linking through the application of the systems approach in a systematic and coherent way the disparate social factors and mechanisms that are involved in creative activity and to describe and explain different forms and mechanisms of creativity and innovative development.

${ }^{1}$ This three-part article draws upon earlier work, T. R. Burns and N. Machado, "The Sociology of Creativity," CIES e-Working Paper No. 196/2014, CIES-ISCTE Lisbon University Institute, Lisbon, Portugal.

${ }^{2}$ Elements of agency-structure-dialectics (ASD) were first formulated by the sociologist Walter Buckley [9, 10], drawing on general systems concepts and applications in the natural sciences, engineering, and mathematics (other approaches were developed by Talcott Parsons [56] and Niklas Luhmann [49] (see [18] on systems theories in sociology and [19] concerning ASD theory). Buckley and a number of those following him and in some cases collaborating with him (Margaret Archer, Tom Baumgartner, T. R. Burns, Philippe DeVille, David Meeker, Felix Geyer and Johannes van der Zouwen, among many others contributed to developing a sociological systems theory variant incorporating general system concepts which were given meaningful social science definitions and interpretations and also incorporated into the framework many of core sociological concepts.
We introduce in this first part of the article a theoretical model taking into account the social embeddedness of agents, either as individuals or groups, in their creative and innovative productions [41]. The agents are socialized agents, carriers of socio-cultural knowledge, including some of the knowledge potentially useful in concrete innovative/transformative processes. In their creative activities, they manipulate symbols, rules, technologies, and materials that are socially derived and developed. Their motivation for doing what they do derives in part from their social roles and positions; in part in response to situational incentives and opportunities, many of which are socially constructed, shaping their interaction situations and domains. Their capabilities including their social powers derive from the culturally and institutional frameworks in which they are embedded. In carrying out their actions, agents mobilize resources through the institutions and networks of which they are a part. As social agents, they are carriers of multiple values and motives and culturally established ideas, strategies, and practices (a "cultural tool kit") [68]. Their innovative activities are social actions, given meanings in cultural and institutional terms in the domains or fields in which they engage in creative activities.

The article applies the sociological systems framework, ASD, to describe and analyze creative activity and innovative developments which are diverse and illuminating of human creativity. ${ }^{3}$ The approach shares with key psychological system theory approaches in the area of creativity consideration of major concepts such as "persons", "leaders," "processes", "products", and "places " (see Table 2) but extends these to include additional factors such as social structures and material resources, social powers, selection mechanisms (e.g., acceptance or rejection), and institutionalization. Moreover, the complex of factors identified and analyzed are specified in this article in sociological terms. The models enable us to distinguish between and analyze processes of creative origination/formation, on the one hand, and processes of institutional acceptance and realization, on the other hand. In addition,

${ }^{3}$ Burns [18] provides an overview of sociological systems theories, in particular, Parsons [56] and Wallerstein [70] as well as Luhmann [49], but to our knowledge, neither in their theorizing nor in empirical studies did they focus particularly on human creativity, although Parsons recognized the importance of innovation, in, for instance, formulating the "adaptation function" (A) in his AGIL scheme. Zeleny [75, 76], drawing on autopoiesis theory formulated a social systems theory, which he applied to creativity in networks (see Part II of the article). 
the work introduces and applies major sociological concepts such as rules and rule regimes - norms, roles, institutions, and cultural formations - in general, social structure. ${ }^{4}$ Moreover, it identifies among the components of rule regimes socially based creativity production functions that are likely to generate innovations. Finally, power considerations are part and parcel of the analyses, for instance the role of the state as well as private interests and social movements in initiating, facilitating and/or constraining innovations and creative developments in society.

In our sociological systems perspective,

(1) Creativity can be systematically treated to a great extent as social, cultural and institutional phenomena as much as psychological and/or biological.

(2) The sociological systems model outlined here helps to conceptualize and analyze creative activity in a perspective differing from the system approaches found in psychology and management studies, in part by consistently stressing and explicating the social dimensions of human creativity, including the socially based facilitators and constrainers of creativity, especially agential and social organizational factors.

The most obvious sociological instances of creativity are found in innovative groups and communities. But even "individual" innovators are located in culturally and socially established fields which provide symbols, concepts and models, established rules and norms, technologies and material resources as well as creativity strategies and production functions.

(3) The approach can be used also for policy purposes [22] for instance, in supporting and guiding research and development and facilitating transitions to new societal arrangements, for instance, to accomplish sustainability (see Parts II and III; also [5] and [74]).

In sum, our sociological systems approach identifies multiple contextual factors - material, social, normative, economic and political - which play a role in driving, facilitating, and realizing creative initiatives, on the one hand; or, constraining or blocking creative processes and developments, on the other hand. It stresses multiple drivers: curiosity, fun, need,

\footnotetext{
${ }^{4}$ Most human social activity - in all of its extraordinary variety is organized and regulated by socially produced and reproduced rules and systems of rules $([11,15,20,36,39,42]$, among others).
}

challenge of solving a problem, the drive for finding better or more optimal solutions, the pursuit of fame and fortune, competition and conflict among agents, and more. It also identifies the actors and mechanisms that play a significant role in the acceptance, incorporation, and institutionalization of innovations and creative developments in given social contexts as well as key determinants of non-acceptance and blockage of the acceptance and institutionalization of innovation. Throughout, there is a consideration of power and resource control, interest configurations, and oppositional processes.

\section{Creativity and creative operations}

\section{What is creativity, creative action?}

Creative human action is universal (see, for example, Table 1). ${ }^{5}$ It relates to innovation, invention, discovery, design, creation, formation, origination - there is a complex of such terms and concepts. It is observable in the actions of individuals, networks, groups, organizations, entire communities, but, as we stress, it is above all social in character-hence, the importance of sociological treatments of it, as we propose in this article [44].

Creativity entails a process of originating, transforming, or adapting ideas, artifacts, systems, a sector or domain, states of the world, or any other entity which is constructed as differing or deviating from what already exists in the context, for instance, a particular field or institutional domain. ${ }^{6}$ As Boden states [8:1], "ideas" encompass concepts, poems, musical compositions, scientific theories, cooking recipes, choreographs, jokes, etc.; "artifacts" include paintings, sculptures, steam engines, vacuum cleaners, pottery, cosmetics, platform shoes, jewelry (see Table 1 below).

Our conception emphasizes process as well as product: creativity involves one or more creativity production functions; novelties are the products or

\footnotetext{
${ }^{5}$ Creativity can be seen in most everyday activity, not just in the arts, sciences, and technological development (as Table 1 suggests). People try, for instance, to solve problems confronting them that may require innovation - because old solutions do not work or new problems arise without apparent solutions using the established problem-solving tools.

${ }^{6}$ The U.S. Patent Office (and multiple levels of U.S. courts) have wrestled with concepts of "discovery", "invention", "novelty", "innovation", "creation". An established, general principle holds that patents are granted to "whoever invents or discovers any new and useful ... compositions" [47:83]. Laws of nature, manifestations of nature, and natural phenomena are to be excluded, even if great human ingenuity and inventiveness are involved in their discovery.
} 
outputs. $^{7}$ Also significant are the agent(s) involved in the process, their particular capabilities and access to resources (materials and technologies) used in originating, shaping, generating innovations and creative developments.

Note that our conception implies that an "innovation" need not be a first instance - it may have been already created in another time and place. But to be defined as a novelty, it needs to deviate from, or be original in relation to, existing entities in the context in which it is produced - it is "new to the context."

Our conception does not - in contrast to most approaches - require that the innovation be usefuladaptive, valuable, appropriate or accepted for inclusion in a field or domain. These processes of acceptance and institutionalization entail other mechanisms and development, as formulated in out models in Parts II and III.

Innovations or created entities entail concepts typically with names - in the agent's or agents' cognitive framework. Typically, it has a defined purpose or purposes (although it may fail to function according to purpose). It also has a structure with one or more components or subsystems that serve its practical functioning or overall purpose. Associated with any such systems is a complex of rules concerning practical matters of use (how to use and possibly how to maintain); other rules concern access and ownership (who has rights to access and use, and when and where).

Our conceptualizations and models as well as selected illustrations are elaborated below (as well as in Parts II and III).

\section{The Extraordinary Creativity of Human} Agents

There is an extraordinary diversity of human creations and innovations, distinguished by their originality, their usefulness in many instances, and their aesthetics. Through their interactions and initiatives, actors produce to varying degrees innovations encompassing not only new technologies and socio-technical systems, new products, but social or user practices as well as cultural discourses, narratives, and symbols. An innovator tries or tests alternative(s), for instance, out of curiosity or playfulness with others; or, the innovator(s) solve(s) hitherto unsolved problems, or develops

\footnotetext{
${ }^{7}$ Innovations may be designed and constructed either as a sym-
} bol or symbol complex (a narrative, painting, or a mathematical formulate), a conceptual system such as atomic theory or game theory, consumables, or a socio-technical system or production function which exploits one or more basic causal process(es). solutions to problems others have solved differently, or develops novel products - the entity created or produced is referred to as an innovation or creative development.

In principle, the variety/diversity of creations is unlimited and continually expanding, as human agents develop new concepts, new powers, new technologies and techniques. One basis for continual innovation and creativity is the ceaseless identification through observation and research of new types of causal and control mechanisms. Many new powers are constructed by controlling or harnessing causal mechanisms or operations (discovered or constructed) [20]. Examples of new "types of power" include: (i) Utilizing the knowledge of the life sciences (for example, genetics, genetic engineering) there is increasing power to manipulate, change, reconstruct life processes of plants, animals, and humans. (ii) Using knowledge of psychology and the other social sciences, humans have developed new powers to influence behavior including forms of advertising, propaganda, brainwashing and, for example, utilization of the "Stockholm Syndrome". (iii) The WWW and other social network technologies enable individuals and groups to reach large populations. Thus, there have emerged forms of mass persuasion and the mobilization of people and resources in order to influence politics and policies. NGOs are very active in all of this as are the social network media.

Innovation has two main themes according to Arthur [3:164] "One is this constant finding or putting together of new solutions out of existing toolboxes of pieces and practices. The other is industries (sectors, domains, fields), constantly combining their practices and processes with functionalities drawn from newly arriving toolboxes, and new domains. This second theme, like the first, is about the creation of new processes and arrangements" (our italics). The result is a cascade of new processes and arrangements, new ways of doing things, not just in one area of application but across the economy and society. Such diversity of creativity conceptually and empirically -- is illustrated below and especially in Part II.

Table 1 emphasizes the range and variation of creativity, in all areas of human activity, extending from science and mathematics, practical as well as recreational technologies, ${ }^{8}$ administrative and

\footnotetext{
${ }^{8}$ The practical as well as the entertainment aspects of some technologies are exemplified in the evolution of skiing, an activity that originated in Norway and Sweden as early as 5000 B.C. using a relatively thin plank of wood (and a pole) for practical transport purposes, but evolved during the 1800 s into recreational, exercise, and competitive forms. Skiing sports themselves diversified into a number
} 
Table 1

Examples of the extraordinary diversity of human creativity

\begin{tabular}{|c|c|}
\hline Creativity in Weaponry and Killing & $\begin{array}{l}\text { - Human history of developing military formations (the Greek Phalanx, Roman } \\
\text { Legion, organized cavalry, panzer division, etc.) } \\
\text { - Development and use of nuclear weapons, chemicals, biological weapons, and } \\
\text { other WMD }\end{array}$ \\
\hline Creativity in Political Forms and Strategies & $\begin{array}{l}\text { - State formations (3000BC-2014+) } \\
\text { - Regulatory and governance arrangements (see later) } \\
\text { - Democratic and totalitarian political parties }\end{array}$ \\
\hline Creativity in Technology and socio-technical systems & $\begin{array}{l}\text { - Genetic engineering techniques and GMO products, } \\
\text { - Energy technologies, communication technologies, organ transplantation }\end{array}$ \\
\hline Creativity in Science & $\begin{array}{l}\text { - Development of concepts such as "atoms", electrons, "quarks", "black holes," } \\
\text { "dark matter," } \\
\text { • Germ theory of disease, vaccines, antibiotics, DNA } \\
\text { - In the social sciences, the creation of instruments to measure public opinion } \\
\text { ("surveys"); demographic models, simulation models; concepts such as policy } \\
\text { paradigm, meta-power, game theory, sociological game theory; in the biological } \\
\text { sciences, }\end{array}$ \\
\hline Rule systems: & $\begin{array}{l}\text { - Languages, etiquette, rituals } \\
\text { - Creation of legal systems, the concept and system of rights, institutional } \\
\text { arrangements, } \\
\text { - Commercial Law }\end{array}$ \\
\hline Creativity in Thinking, Believing & $\begin{array}{l}\text { - Gods and mythologies } \\
\text { - Creation and formation of discourses about "soul," "spirits," "supernatural } \\
\text { beings," "immortality" }\end{array}$ \\
\hline Organizational and administrative forms & $\begin{array}{l}\text { - Formal associations, partnerships, limited liability enterprise, Factory systems, } \\
\text { task forces, investigative bodies; Corporate arrangements, Franchise } \\
\text { arrangements }\end{array}$ \\
\hline Sports and game creativity: & $\begin{array}{l}\text { - Creation of a sport or type of sport, e.g. spectator sports (tennis, football, } \\
\text { cricket/baseball, basketball). } \\
\text { - Multiple forms of skiing } \\
\text { - Parlor games including card games, chess, checkers, Go, computer games, etc. }\end{array}$ \\
\hline Creativity in aesthetics and imagination & $\begin{array}{l}\text { - Creativity in the visual arts, for instance a diversity of perspectives: French } \\
\text { Impressionists, Cubism, Surrealism, Abstractionism, etc. } \\
\text { - Creativity in music (Gregorian chant, polyphony, counterpoint); New techniques } \\
\text { in opera, dance, theatre } \\
\text { - Invention of the novel, "detective story", "travelogue", "romance," "science } \\
\text { fiction"; mixed; Creation of literary characters: Don Quixote, Brothers } \\
\text { Karamazov, Frankenstein, Dracula, Sherlock Holmes, Maigret, Miss Marple, } \\
\text { Batman \& Robin, Superman, James Bond, etc. }\end{array}$ \\
\hline Creativity in lifestyle, role behavior, dress & $\begin{array}{l}\text { - Creation of non-mainstream lifestyles: Bohemian, hippie, yippie, yuppie; } \\
\text { Change in gender identities - clothes, shoes, hair, behavioral codes, use of } \\
\text { cosmetics, and more. } \\
\text { - "Burning Man Project". Annual social experiment since } 1968 \text { in Nevada (Black } \\
\text { Rock Desert) entailing sexual experimentation, psychedelic drugs, concepts of } \\
\text { community experience, art, radical self-expression with as many as 70,000 } \\
\text { participating. } \\
\text { - Furry sub-culture" where participants dress up to become live versions of diverse } \\
\text { stuffed animals at their gatherings and maintain their fuzzy identity over } \\
\text { extended time frames. }\end{array}$ \\
\hline
\end{tabular}


Table 1

(Continued)

- In contemporary times there is continual innovation in hairstyles, clothes, shoes, tattooing, piercing, use of cosmetics

Creativity in the home and home life

- Home (inside and outside architecture, decorations, plant selection and gardens), Furniture, kitchen design, kitchenware, bedroom, beds, mirrors, etc.

- Food and dietary patterns

- Sexual practices (also developed of course outside the intimacy settings of the home)

- House cleaning and sanitation, house drainage

other organizational apparatuses, ${ }^{9}$ diverse forms of entertainment, ${ }^{10}$ artistic perspective and practices ${ }^{11}$ the creation over centuries and across continents of multitudes of monsters, ${ }^{12}$ etc. Unfortunately, there is a

of innovative forms and technologies: downhill, cross-country, freestyle skiing, snowboarding, and heliskiing (use of helicopter to take skiers up to unreachable peaks), among others. All point up the powerful, diversified creativity of humans - in this case in the field of winter sports.

${ }^{9}$ In the long evolution of administration or "bureaucracy" (in one or another form), ways were found to combine and manipulate social relationships in an organization of actors in such a way as to control their behavior in more or less precise ways - such a social "apparatus" could and continues to be used for systematic control of people and resources to realize productive as well as destructive purposes.

${ }^{10}$ For instance, the potential human receptivity for entertainment that in early societies was fulfilled by public spectacles and storytelling came to "require" (or called forth) in a more differentiated, urbanized world a panoply of sports, dramas, musical performances, moving pictures. What appear to be simple needs multiply into subgenre - thus, modern people develop interest in many kinds of music, dramas, sports, etc. (see [3:175])

${ }^{11}$ John Parker and Ugo Corte, drawing on Becker [6] and Farrell [32], point out that creative art groups develop entirely new artistic perspectives and practices, develop/acquire and use new materials and technologies, concepts and forms that deviate from established artistic practices and expressions leading to new artistic movements ("Placing Collaborative Circles within Fields," ms, 2014:10). The Impressionists come to mind, which Farrell [32] investigated, but also the groups involved with Bauhaus, Expressionists, Cubists, Andy Warhol, and many others.

${ }^{12}$ The creation of monsters is not a Hollywood invention, although Hollywood has been highly inventive in this respect and also prepared to make use of historically established monsters. Ancient Egypt, the Greeks, the Aztecs, many traditional and prehistorical societies and, of course, our contemporary societies, above all in films and other forms of visual arts - have done and continue to do this. Many "monsters" have been imaginarily constructed from the parts of real animals including humans, that is, they are hybrids, for example, the unicorn, sphinxes, flying bulls, centaurs, satyr, Roman representations of a man with a goat's ears, tail, legs, and horns), man's head with a penis in place of the nose, a horse with a single onyx-like horn on its forehead, among others [59, 72]. tendency to overemphasize the locus of creativity in the arts as well as in technology and science. However, in our perspective, creativity is the hallmark of human adaptation, survival, and development. Many opportunities for creativity emerge in the context of diverse and ever-expanding needs or problems to be solved and the solutions that are generated, as suggested in this work.

When it comes to major societal innovations, there is typically a cascade of developments: ${ }^{13}$ diverse creative-destructive processes resulted from, for instance, the invention of the automobile or the transistor or assembly line production robots. Arthur [3:179] points out, “... the transistor entered the collective around 1950 (step 1); replaced the vacuum tube in most applications (step 2); set up needs for the fabrication of silicon devices (step 3); caused the vacuum-tube industry to wither (step 4); became a key component of many electronic devices (step 5); and caused prices and incentives for electronic equipment to change (step 6) ... . listing events this way makes them look too neatly sequential. In practice, they do not follow each other in a tidy way. Often they operate in parallel... And of

\footnotetext{
${ }^{13}$ Arthur [3] stresses the cascade of multiplying innovations and creative developments associated with the emergence of such creations as the automobile and the conception of auto transport. Arthur [3:175-176] writes: "The automobile in 1900 created a set of ancillary needs - opportunity niches - for assembly-line manufacture, for paved roads and properly refined gasoline, for repair facilities, and gas stations. And gasoline in turn set up further needs for refineries, for the importation of crude oil, and for the exploration of oil deposits. Every innovation (for instance in the case of technology) by its very existence sets up an opportunity for fulfilling its purpose more cheaply or efficiently; and so for every technology there exists always an open opportunity (indeed, many possible opportunities). And for another, every technology requires supporting technologies: to manufacture it, organize for its production and distribution, maintain it and enhance its performance. And these in turn require their own sub-supporting technologies."
} 
course many of these events take time to play out. ${ }^{14}$ A technology takes time to diffuse through the economy, and the economy in turn may take several years to adjust itself to the novel technology." The formation of the "factory system" provides an example of a very large-scale cascade. It entailed a complex of interrelated innovations and transformations. Typically in such transformations there was no simple predetermined sequence unfolding but, nevertheless, a social, economic, political, and technical logic to the initiatives and developments $[5,20]$.

\section{Selected systems approaches to creativity}

Systems approaches to creativity are several (see Table 2). They stress that creativity and innovation results from multiple interrelated factors in dynamic interplay. In psychology, there are arguably two leading system approaches: Csikszentmihalyi [28, 30] and Puccio et al. [57] (also see Sawyer [62, 63], and Sterling's Handbook of Creativity [67] which contains articles presenting systems approaches). Both of these approaches see creativity as a systemic process which results in a novel idea or product that is recognized and accepted by others. Puccio et al. [57] combine persons, processes, and leadership in an "environment" or field to produce creative changes (e.g. change in personal, innovation in technologies including built environments, etc). Csikszentmihalyi's approach ([28, 30]) focuses on the interaction behavior between individuals, cultural domains and institutional fields, resulting in creative initiatives and developments (see also Montuori [52] and McIntyre [51]). From the cultural domain, rules and practices are transmitted to, and

\footnotetext{
${ }^{14}$ Some creative developments involve centuries, a very long evolution, indeed. For instance, the development of the germ theory of disease spanned centuries from the invention of the microscope (around 1600) and the discovery of "animalcules" to the ideas of well-known scientists such as Robert Boyle (1627-1691) and Robert Hooke (1635-1703) and later refined by Louis Pasteur and others in the $1800 \mathrm{~s}$. These developments led to our contemporary view of pathogens as agents of disease [33]. On the other hand, some discoveries such as Alexander Fleming's (1881-1995) "discovery" of penicillin seem simple enough In the "discovery" of penicillin, Alexander Fleming's (1881-1955) basic role viewed superficially seem simple and immediate enough. However, his discovery was based on a very developed knowledge framework and set of existing technologies. As Arthur [3] (p.169) points out, "It required biochemical processes to isolate the active substance within the mold, other processes to purify it, and still other ones to produce and deliver it. Penicillin had its parentage in these means and methods..."
}

incorporated in, individuals. The creative products of persons - contributing to variation in an evolutionary sense - are selected for eventual inclusion in the cultural domain through institutional fields involving agents of judgment, for instance "gatekeepers," including experts (this approach shares several commonalities with the sociological systems approached presented below). ${ }^{15}$

The sociological systems perspective (ASD) identifies a few key social components of creative activities. Socially contextualized creative activities call for specification of context(s), the embedded creative agents, the inputs in relation to them (necessary materials, knowledge, knowledgeable agents, etc.) and agents' translation of the inputs into the innovation activities and their outputs - potential creations, transformations, and recombinations (see Figs. 1 and 2). Drawing upon earlier work on the sociology of creativity and innovation (see Section II), we focus attention on the social nature of creative agents (whether individuals or groups), the social character of their actions and interactions (including mobilizing and exercising power, cooperating, competing, and conflicting), the institutional-cultural conditions (social structures) that facilitate or constrain or possibly block creative action, and the conditions that make for receptivity and acceptance of creative action or its products, on the one hand, or its rejection or suppression in the larger societal context, on the other hand. We highlight then the social systemic features of creative action and its possible products. Key features of our sociological systems framework (ASD) are indicated in Figs. 1 and 2 and Tables 2, 3, and 4.

While there are parallels in the sociological and psychological system approaches, there are substantial differences: (1) Social actors, individuals as well as collectives, in the sociological systems framework are not only embedded in social systems but also construct, adapt, and transform such systems including those of which they are a part. They are the major endogenous factors in the construction and evolution of systems and in the production of creative acts and innovation. Such agency is largely social, and its actions and interactions are sociological in character although individual

\footnotetext{
${ }^{15}$ Csikszentmihalyi [28:315-316] rightfully connects a dynamic systems perspective to evolutionary concepts: the production of variation, selection and transmission (see also Burns and Dietz [13, 14]). He [28:315-316] points up the importance of this phase in the establishment and institutionalization of innovation: to be creative a variation has to be adapted to (acceptable to) its social environment and it has to be capable of being passed on through time. This acceptance "criterion" for creativity is repeated in Sawyer [62:214] and is assumed by Amabile [2:1010].
} 


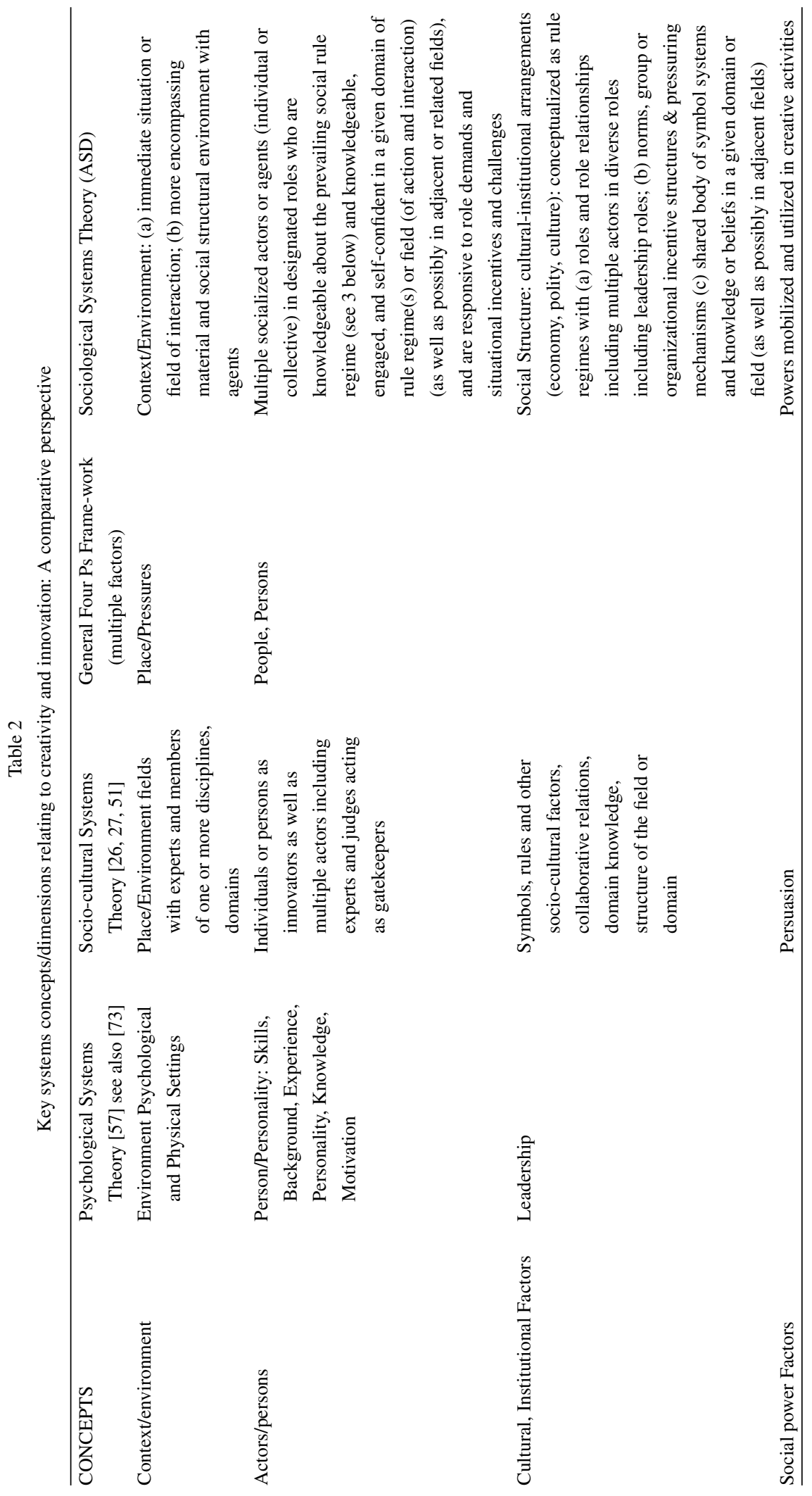




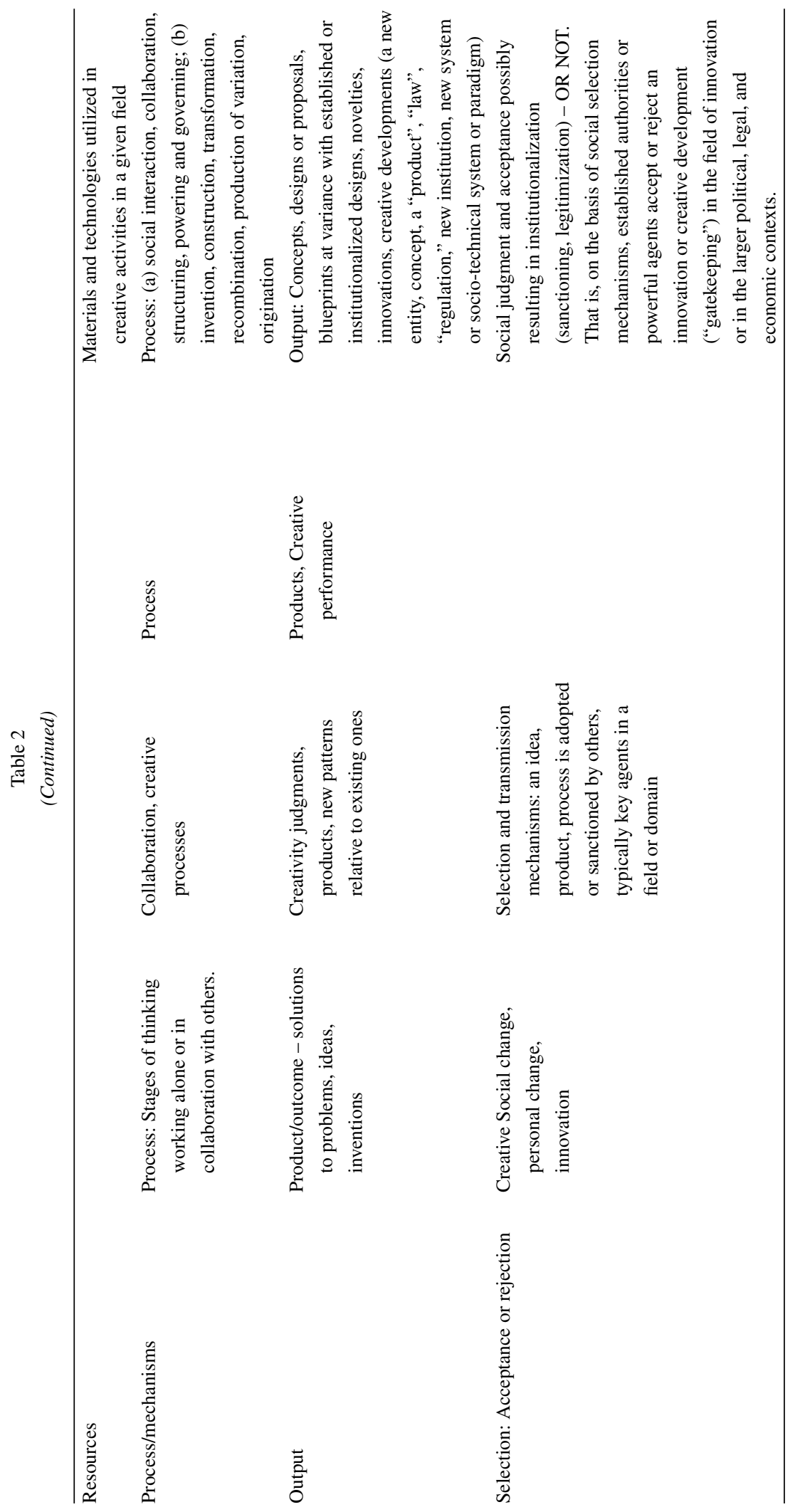


cognitive and evaluative/judgment processes - socially grounded - play a significant role. ${ }^{16}$ (2) ASD theory incorporates in a natural and coherent manner as compared to psychological approaches - the conceptualization of institutions and cultural formations. In general, in sociology there are elaborated structural theories, and applications of these to the analysis of, institutions and culture and, in general, social structures. The ASD approach conceptualizes as foundational in sociological structural analysis social rules and rule regimes. While the latter are systemic in character, they are carried and applied/interpreted in many cases individually. (3) The ASD approach does not assume that creativity - or creative actions and their products - are predicated on social usefulness or even immediate applications - as do most key psychological system theories. Application, receptivity, and judgment of usefulness relate to later phases in innovation developments (see the phase model of creativity and innovation, Fig. 2 and Table 3 ). This is because social acceptance, judgments of usefulness, and institutionalization of innovation are typically key social processes in themselves - often distinct from the phases of creation and innovation per se. The processes making up the "receptivity context" require specification and analysis in order to understand the response to creativity in its social (and economic and political) context. (4) Like other systems approaches, ASD theory recognizes multiple interrelated processes and causal mechanisms, but it particularly attends to and elaborates the causal mechanisms of social agents and social as well as material structures (institutional arrangements, cultural

\footnotetext{
${ }^{16}$ Some actors are better than others at drawing upon and exploiting the opportunities for creativity and innovation in their situations - which derives in part from their history and involvement with others, their knowledge of and ability to draw on the cultural elements available to them in their social fields. They often have learned to see things in new ways, making connections; being alerted to chance and to the opportunities presented by contradictions and complexities, recognizing familiar patterns in the unfamiliar so that new patterns may be formed by transforming old ones, being alert to the contingencies which may arise from such transformations. Traits of creative, entrepreneurial individuals: an ability to think metaphorically or analogically as well as logically, independence of judgment (sometimes manifesting itself as unconventionality, rebellious tendencies, readiness to take risks, revolutionary thinking and acting; a rejection of an inadequate simplicity (or premature closure) in favor of a search for a more complex and satisfying new order or synthesis. Possible naiveté or innocence of vision may be combined with stringent requirements conditioned by judgment and experience (including professional experience). Ability to negotiate verification by judges is a final stage in a creative development. preceded by familiarity with the problem, and selling or buying a new vision.
}

formations, technologies and socio-technical systems) [20]. Social structural and agential factors and mechanisms in the "context of invention" enable or block to a greater or lesser extent initiating actions and the availability of resources and powers.

The three systems approaches - two psychological and one sociological - are summarized below in a comparative table specifying multiple key variables. ${ }^{17}$ The third column lists the "four Ps", multiple factors that several psychologists working in the field of creativity research have identified as universal aspects in their investigations and analyses of creativity and which comprise a system of variables constructed by induction [4, 35, 58, 62, 63].

The sociological systems model of creativity is elaborated in the following sections, stressing the social character of each of the factors of creative action and also the qualitatively differentiated phases of the creative process, whether a single individual is involved or one or more groups and organizations. The theory emphasizes key sociological features from the initial recognition or identification of a problem or idea or want - which is often the point of departure of creative attempts - to its realization in "creative or innovative initiatives."

\section{Sociological systems models of creativity}

\section{Background}

Most scientific work on creativity has been in the fields of psychology and management [1, 26-30, 57, 62, 63-66, 71], among others). Sociology cannot be said to have had an explicit focus on "creativity;" rather, innovation has been the preferred rubric. Nonetheless, there is a body of relevant literature in sociology ([5, 17, 22-25, 32, 34, 43, 44, 54, 55, 74], among others, addressing sociological aspects of creativity, innovation and entrepreneurship. ${ }^{18}$ The particular innovation/creation models, which we present here, derive from a sociological systems framework (as presented in [11, 18-20, 22]). They combine the idea of directed problem-solving and adaptation, innovation and evolution in complex selective environments (Burns and Dietz [13, 14]). The models describe and explain innovation and adaptation, transition, and transformation through the operation of such key factors as human agency and social and material structures.

\footnotetext{
${ }^{17}$ See Lubart [48] for criticism of system approaches to creativity.

${ }^{18}$ Much earlier sociological work is still relevant, for instant the work of Colum Gilfillan [37] and W.F. Ogburn [52].
} 


\section{Context-Dependent Creative Social Action:} ASD Input-Output Model

The ASD sociological systems approach contrasts in a number of ways to psychological systems approaches to creativity emphasizing (as outlined in the previous section): ${ }^{19}$

- Social agents are collectives as well as individuals, both capable of certain forms of creativity in particular fields, in general entrepreneurship.

- Social structure - institutions and cultural formations - based on rule regimes are prominent features of the context of creative action and its outputs in a given field of activity or performance.

- Social action and interaction - the nuts and bolts of creativity - are shaped and regulated by the embedding social rule regimes and material conditions

- Particular production functions - which under some conditions produce novelty with certain likelihoods - are available in the rule regimes applying to one or more fields.

- "Gatekeeper" agents are involved in social structures and mechanisms of judgment, which play a role in the acceptance or rejection of - ultimately, the institutionalization or exclusion of innovations ([28-30]; John Parker and Ugo Corte, "Placing Collaborative Circles within Fields," ms 2014).

- The social context of selection and institutionalization of novelty in more encompassing social systems typically also entails a type of secondary or tertiary innovation in applications and adaptations.

The model below (Fig. 1 and Table 3) specifies contextual factors as well as the key input-output factors: in particular, knowledgeable, capable, and self-confident agent(s) of creative action; creativity production functions (see Section 3, below); appropriate technologies and materials; it suggests creative outputs occurring with varying degrees of likelihood,

\footnotetext{
${ }^{19}$ Several psychological theorists such as Boden [8]; Batey and Furham [4]; Csikszentmihalyi [26, 29]; Gautam [35]; Rhodes [58]; Sawyer [63, 64], among others, have identified some of these same components as ASD (see Table 2), for instance, the creative "process," "creative individuals" or agents with their "knowledge and capabilities," their "relationships" (especially leadership), the "characteristics of the situation/context" influencing actors' motivations and orientations as well as "resource" access and level of availability, "outputs" or products, and the social acceptability of their innovations. Our contribution is to sociologize these and to view them along with other factors as a general system of interrelated parts in a given context, as outlined in the following sections.
}

depending on input factors and production processes (discussed below). ${ }^{20}$ The field $F$ consists of an action and interaction context with particular actors and their relations, rule regimes, ${ }^{21}$ established socially shared concepts and models, technologies and materials, and production functions (John Parker and Ugo Corte, "Placing Collaborative Circles within Fields," ms 2014).

The complex of key interrelated factors presented in the ASD input-output model below are - in a nutshell (see Table 3).

\section{Creativity and Innovation Production}

\section{Functions [12]}

A production function is a rule complex (see Fig. 1). It is characterized by such rules as: (1) those directing and regulating the performance of a process related to a purpose, value, or goal; (2) participatory rules specifying the appropriate actor (or actors) to engage in the process (in the case of multiple actors, their role relationships and tasks in the production are typically specified); (3) rules concerning the appropriate technologies and resources (materials) deployed in the activity; (4) usually the rules also specify the particular time and place for the production activities [15].

Production functions, as rule complexes, vary in their degree of specification, organization, and coherence. For instance,

(1) Some are highly organized and routinized complexes combining specified tasks, resources, and actors to perform particular activities and to accomplish certain outputs. ${ }^{22}$ In the case of a group, members and their roles are specified by the rule regime, defining, among other

\footnotetext{
${ }^{20}$ As discussed later, the outputs, in particular innovations and creative developments, are subject to judgment and acceptance/rejection and eventually possible institutionalization (see Part III and Figs. 3a and 3B).

${ }^{21}$ The rule regime identifies and governs to a greater or lesser extent-depending in part on external agents and conditions -agent(s) identity and participation in field $\mathrm{F}$, norms, roles, and role relations and provides rules as the basis of values, beliefs, passions and production functions. The shared knowledge of the rule regime defines relevant concepts, designs, potentialities in the Field F (as well as possibly other fields) and the commitments and goals some of which drive creative activity. The rules of the regime govern to a greater or lesser extentthe material resource base; materials, technologies, space/places, and time.

${ }^{22}$ Organized-routinized complexes for key collective and production processes are found in earlier work: models of administrative arrangements are found in [11, 15, 20]; models of negotiation procedures are found in $[15,22,60]$; collective deliberation and decision-making/conflict resolution are considered in [21].
} 
Table 3

Key components of ASD input-output model

Contexts: Social and ecological contexts including interaction situation(s) in F.

Relevant Rule Regime(s) applying in a given field F (or fields)

Agents with appropriate knowledge, capabilities, and motivation in field $\mathrm{F}$ or related fields

Appropriate Relations and interaction patterns among agents (roles and social structure) defined and regulated by rule regime(s) in field $\mathrm{F}$

Appropriate resources (materials and technologies) for agents' creative strategies and production functions in field $\mathrm{F}$

Production functions or strategies in field F (as part of the differentiation of the "creative process")

Outputs: successes and/or failures; their likelihoods

Acceptance judgment in as well as outside F

things, leadership roles and task-actor-resource relations.

(2) Production functions may be relatively open and flexible but nonetheless serving as a frame for conceptualizing, organizing and regulating key group activities and collective judgment and decision processes. Thus, incomplete functions/algorithms open the way for participants to fill in some of the unspecified dimensions and parameters (often by taking into account contextual conditions, contingencies, "rules of thumb" and other heuristic principles); actors in specific roles with specified objectives or purposes may be left to work out how to perform or realize specified objectives (that is, there a high level of discretion about means).

(3) Highly specified and organized production functions can be activated and performed routinely in an appropriate context. More incomplete, underspecified production functions (such as those consisting of heuristics and "rules of thumb") have to be applied and worked out by the agent (in the case of a group, multiple agents) in practice, which typically entails judgment and learning processes, even trial and error.

The following section presents a selection of creativity production functions.

\section{The Modalities and Diversity of Creativity} Production Functions

Creativity production functions are highly diversified in part because they are context sensitive, differing in different fields of activity and organizational contexts and with respect to different objects of innovation. In the course of trying to solve problems, an agent or agents initiates innovative activities with different ambition levels, strategies, means or "toolkits" [68], and resources. The core idea is that of a general problem-solving model whereby new solutions and discoveries may be found, or established older solutions may be adapted or transformed.

There are at least five basic modalities of creativity production: origination/formation, transformation, combinatorics, adaptation, and dialectics. Typically, there are composite forms. Below we specify and provide selected illustrations of the different types of creativity modalities:

A. Origination/Formation. Origination/formation entails a process of originating more or less "from scratch" a completely new idea, artifact, or phenomena [3]. One starts out with a problem or challenge without established models or designs for solving it. A motivated innovator or entrepreneur may try any of the dialectical modalities such as trial and error, experimentation, or "heuristics" (see below). Origination entails forming in a particular social time-and-space context an element or complex of elements that did not exist previously, whether a symbol (for instance, the 0,1 , and $\infty$ symbols), concept (atom, nucleus, game conception, cognitive dissonance concept), entirely new technology or socio-technical system (nano technologies, genetically modified food), built environment (nuclear energy facility, a new research construction such as the proton accelerator (ESS) in Lund, Sweden), institution (a legal or other rule system), new forms of social power based, for example, on psychological or pharmaceutical means). For instance, the concept of limited liability for all joint-stock companies was established in the U.K. by the Joint Stock Companies Act 1856; such companies limited liability for individual shareholders as opposed to a partnership with complete individual responsibility for all participants also such joint stock companies were defined as "persons." Or, the poisonous mustard gas in the First World War (first created and applied by Germany, 1917); the "Bessemer process" (1856) entailed a new method 


\section{INPUTS}

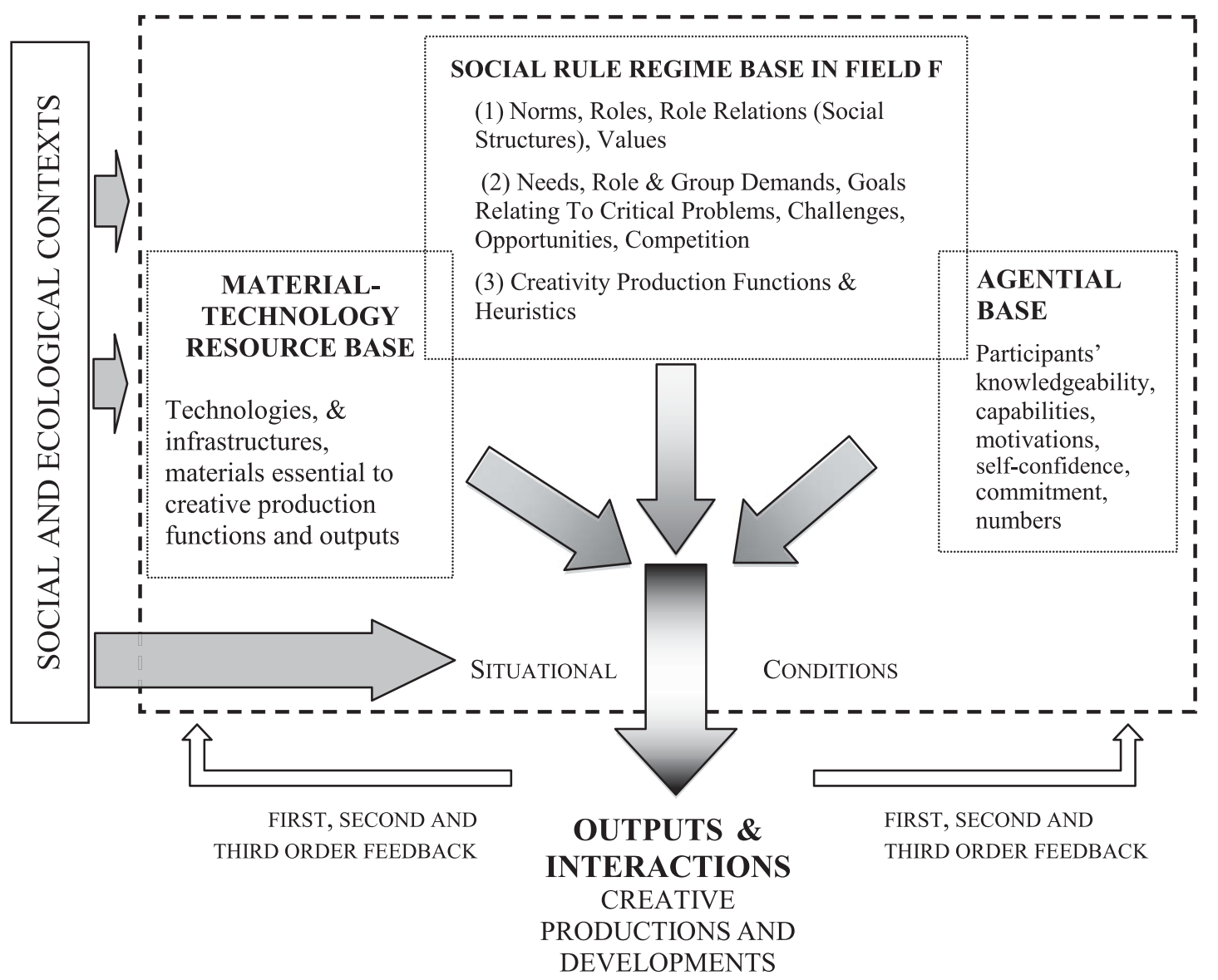

Fig. 1. Systems theory input-output model of creative action.

for making purified steel by blasting compressed air through molten iron to burn out excess carbon and impurities.

Generally speaking, much origination/formation is realized through "capturing" and controlling or manipulating existing natural, technical, social phenomena for particular human purposes or goals. The phenomena may be gravitation or the flow of water, which can be harnessed for energy or agricultural purposes; or human relationships may be established - or existing ones manipulated - so as to realize opportunities for gain or to avoid losses.

B. Innovative Transformation. Transformation entails restructuring or remaking an element or complex of elements so that it differs qualitatively and quantitatively from what there was before the transformative action - whether we are considering the transformation of an artifact, concept, belief system, or rule and symbol system. $^{23}$ (i) One may take a copy of an entity and modify or transform some or many of its properties and mode of functioning, particularly in relation to a new context of application. (ii) In genuine innovative transformations, one replaces one or more components and/or relationships with a substantially different

\footnotetext{
${ }^{23} \mathrm{Or}$, particular performance techniques and roles in the field of film: Charlie Chaplin, Buster Keaton and others were highly entrepreneurial in adapting and eventually transforming their techniques and skills in the transition from silent movies to talking movies. Roles were also transformed and developed, for instance Charlie Chaplin's original clown role was transformed into the very different clown creations of Chaplin's daughter, Victoria, and the great performer Russian Oleg Popov.
} 
or new component or linkage, adding to, subtracting, or replacing parts and wholes. ${ }^{24}$ (iii) Reframing an existing element or complex of elements so that it is treated or used in a significantly different way than previously. For example, tanks (from World War I development) were combined into a new kind of military unit, the "Panzer division" rather than being deployed simply as an "iron horse" accompanying troops [46]; in the field of art, a porcelain urinal ("Fountain") in 1917 was made into an "art object" (Marcel Duchamp). (iv) Radical transformation typically entails a paradigm shift from an old paradigm (complex of dimensions) to a new one [22]. The new revolutionary paradigm is originated on the basis of an entirely new conception or principle, new methods, and production processes but also adaptations. Examples are many of the socio-technical innovations in the industrial revolution, quantum and relativity theories in physics, the germ theory, the theories of genes and DNA, radically new technology developments such as nuclear energy, nano-technologies, and GMOs (several of these to be discussed in Parts II and III).

C. Combinatorics. Combinatorics entail types of transformation, combining and re-combining components and linkages of a system. The resultant system differs significantly from the original (dissimilar in qualitative and/or quantitative terms).

We find many instances of transformative combinatorics derived from following particular forms and procedures, for instance: (i) An entity $A B$ is differentiated into separate and distinct entities, $\mathrm{A}$ and $\mathrm{B} .{ }^{25}$ Or, the operation of fusion where $\mathrm{A}$ and $\mathrm{B}$, as separate entities, are brought together into a single unit $\mathrm{AB}$ (this will involve solving interlocking or integration problems): for example, hybrids, fused biochemicals, or fusion of social organizations and networks. In general, these transformations encompass new ways of interweaving and interlocking - or alternatively, separating different kernels of knowledge, ideas in science and culture, or combining musical themes and voices (Bach's polyphonic music was based on combining different "musical voices"), verses, styles, story genres, social organizations and networks. (iii) The quality or structure of a complex of elements is changed by adding

\footnotetext{
${ }^{24}$ Not all transformations result in novelty; some maintain identity, established conditions and processes. These would not be seen as innovative transformations, but rather "reproductive."

${ }^{25}$ Examples are many, for instance, distinguishing the components or subatomic particles of atoms, or stars from planets, or separating sociology from psychology or economics.
}

or removing, or replacing some or all of the elements with different elements, or by changing, removing, or replacing relationships.

In general, new elements (concepts, designs, technologies, socio-technical systems, rule and symbol systems, social systems) may be constructed or deconstructed from elements that already exist, that is, these are available as possible building blocks - elements for the construction of still further elements and systems. For example: radio transmitters and receivers, in conjunction with other elements, made possible an entirely new complex invention, the socio-technical system of radio broadcasting [3:167-168]. In the human formation and evolution of new complex structures, combinatorics is prominent and common.

D. Adaptation/Modification. Adaptation of an concept, technology, symbol, or entity $\mathrm{X}$ entails, for instance, applying it under similar circumstance but doing so differently than in the past - making adjustments in it so that application is feasible, such as changing the values of its parameters.

Simply applying $\mathrm{X}$ in a new context typically requires making some adjustments so that X "fits" properly the new context, and this entails innovating. ${ }^{26}$ For instance, (i) In the construction of the automobile, the horsedrawn wagon or carriage was adapted to use with an electric or gasoline driven motor and a steering device, among other technological adaptations. (ii) The establishment of Xerox's PARK PC unit entailed adapting a taskforce model of social organization to the IT setting with the intent to develop a PC, engaging a creative task force, and, among other things, introducing explicit norms about group sharing of data and intensive collaboration (they eventually succeeded in developing a PC but marketing it was rejected by Xeros (see Part II). (iii) In general, existing systems may be adapted parameterwise or structurally so that they can be used for purposes or in a context other than that for which they were designed or originally envisioned. Even in starting an origination process from what appears to be scratch, an innovator may have confronted similar problems in the past and may be able to adapt earlier innovations for her present purposes, for instance, in developing a vaccine, as now in the current efforts to create a vaccine against ebola; procedures are being tried that have been

\footnotetext{
${ }^{26}$ Many "innovations," for instance a concept, symbol, artifact, or socio-technical system, may entail simply importing it to a new context, or using it in a new way or for a new purpose. This type of invention differs from genuine origination or novel creation (see the modality of "adaptation") but is one of the modalities of creativity production
} 
developed in earlier vaccine development such as using live but weakened pathogens, using dead pathogens, or utilizing genetically manipulated pathogens.

E. Dialectical Production Functions and Strategies for Creativity. Dialectics encompass less directed, more fluent creativity strategies and production modalities than those presented above; nevertheless, they may lead to innovation and creative development. In our perspective, "dialectics" concerns fostering the interplay between different perspectives or paradigms, problem-definitions, solution-complexes so as increase the likelihood of generating innovations and creative developments. This is suggested by the "Hegelian/Marxian" formula, thesis-antithesissynthesis. Dialectics is illustrated in processes such as: (1) the development of knowledge through debates and scholarly defenses and dialogues; (2) initiating alternative exploratory investigations combined with hypothesis generation and critical analyses; (3) initiating "trial and error" strategies as well as more systematic forms of experimentation to gain insight, to make discoveries, and gain understanding for purposes of generating ideas and innovations; (4) recruiting diversity and "mixing" in contact or communication networks participants with new or different perspectives or with special knowledges (consultants, experts from other fields or other traditions) in order to generate innovation and creative development; (5) arranging brainstorming $\&$ articulation of competing alternatives; (6) using one or more heuristics including "rules of thumb" [69]; ${ }^{27}$ (7) arranging play and visionary experiences among participants to provide openings to and stimulation of the imagination; ${ }^{28}$ (8) introducing or activating social norms and values to encourage innovation and creative development as well as alertness to potential and opportunities (see below).

\footnotetext{
${ }^{27}$ Heuristic techniques range from utilizing "rules of thumb" to trial and error strategies. Instances of heuristics are, for example: (1) start with one or more concrete cases in order to articulate a more general case or model; (2) or, start with a general conception and search for one or more areas of possible application in order to elaborate or adapt a general conception; (3) solve a simpler version of the problem at hand, then elaborate or adapt the solution when connecting back to the original case; (4) solve a related problem and determine potential parallels of the problem-solution complex to the original challenge; (5) transform the problem into something different, which proves solvable and then transform back to the original state, making use of insight gained into solution(s) obtained.

${ }^{28}$ Much creativity has its source in visionary experiences and dream worlds - this is above reason and logic. In order to express such insights and inner experiences, an innovative language may be adopted or invented with new images, concepts, and meanings.
}

Such dialectical strategies and modalities of action are intended to help generate ideas, alternative conceptions of existing entities, proposals for creative initiatives - at the same time, they require for success the encouragement of alertness to chance happenings and possible discoveries, to unintended developments, to serendipity, to mistakes and accidents in one's own explorations and experiments as well as those among competitors or others working in the field or related fields.

A principle idea in back of the multiple modalities of creativity is that they make up a spectrum of socially established and available processes for constructing new entities or rearranging entities or transforming them. Typically they involve operating on and with a set of already existing objects, rules, representations, paradigms, or notations as well as institutionalized methods, strategies, and production functions (see Part II). ${ }^{29}$

\section{The ASD Phase Model of Creativity Production} and Acceptance/ Institutionalization

An innovation or creative production process typically consists of a series of activities differentiated into phases (Fig. 2 and Table 4 highlights the qualitatively different activities). The ASD model of creative production processes identifies the multiple phases (seven) in creative action and innovation as well as reception/acceptance, legitimation, and institutionalization. ${ }^{30}$ Two major contexts of social action and interaction are distinguished in the phase model: (A) the context of creation (Phases I, II, and III) and $(B)$ the context of social acceptance (or rejection), legitimation and institutionalization (Phases IV, V, VI, and VII). Note that Figs. 1 and 2 specify agency (actions of an innovator or entrepreneur (individual or collective)), resources, institutional and group structures (rule regimes), interaction/communications including leadership relating to producing novelty as well as relating to "acceptance" (or rejection) and possible institutionalization of novelty or a creative development.

The creativity production process is not linearbut loops backwards and forwards. For instance,

\footnotetext{
${ }^{29}$ Csikszentmihalyi [28:315] points out that "Original thought does not exist in a vacuum. It must operate on a set of already existing objects..." (or uses them as a point of departure for applying creativity production functions or modalities (our comment)).

${ }^{30}$ Farrell [32] developed a phase model for his creative collaborating groups, but the model concerned group development rather than the process of creativity per se. But one might link the two phase processes, to show how stages of group development influence innovation and creative development.
} 
negotiation or blockage in Phases IV, V, VI, or VII may lead participant(s) to return to earlier phases, possibly restarting the process in Phase I, II, or III. Also, creative processes may be aborted, for instance in a particular phase, because key agents exit or essential resources cease being available or are not obtainable, or the process and/or its products are suppressed because of external pressures. Even key participants in an innovative development may decide, for instance in Phase IV, to terminate an innovation initiative because they morally reject the creation or fear the reaction of powerful agents in their environment (or, on the basis of further analyses, they anticipate the unsustainability of the creation (see discussion in part II about the personal computer case).

\subsection{Differentiation in the phases}

Phases differ in terms of key participating agents, their appropriate rule regimes, their resource bases, and contextual conditions; of particular interest in our studies is the social organization of the creative context, whether a diffuse culturally knowledgeable community, network, informal group, large-scale organization, or an entire society (illustrations are provided in Part II).

(i) In the phase cycle, phases I, II, and III are characteristic of "the socio-cultural context of the production of novelty" while phase IV, V, VI \& VII refer to the "socio-cultural context of acceptance/selection and institutionalization." 31 Social roles, resources, and strategies as well as, of course, social organization and interaction patterns differ in these different contexts. In particular, the agents involved - and the roles they play - shift to a greater or lesser extent in the phases of the cycle. In each phase there will be variation in the knowledge and skills mobilized, and the capabilities and leadership called for. In line with this variation, involvement/motivational factors are likely to differ, e.g. a shift occurs from drivers such as curiosity or group sociality to considerations of economic gain or

\footnotetext{
${ }^{31}$ In other words, the model here distinguishes analytically between discovery or invention and its acceptance/rejection in a socio-cultural context. The psychology theorists define an innovation as both original and useful as well as sustainable within a given field [29, 31, 63, 64]; the sociologists John Parker and Ugo Corte also take this position in "Placing Collaborative Circles within Fields," $\mathrm{ms}, 2014)$. We consider an innovation as a product of the processes of generating novelty. The acceptance as well as institutionalization of novelty entail social processes, analytically distinct from the creation/innovation processes, hence, our specification of the context of acceptance, legitimation, and institutionalization.
}

recognition, or consideration of social and environmental impacts and reactions. Such shifts make for different sources of conflict - and their possible resolutions. For instance, conflicts might shift from substantive cognitive or technical conflicts to conflicts over how much to stress economics or how gains and recognition among those involved in the innovations should be distributed.

(ii) In phases I, II, and III, actors involved in groups may explicitly or tacitly agree or disagree about the nature of the problem or challenge and the appropriate way to think about and deal with it in the innovation process; disagreement may arise also about what can be considered a particular "solution" - or whether or not a particular solution can be actually be accomplished. Phases IV, V, VI \&VII may be characterized by conflicts among the actor(s) involved in creative initiatives, on the one hand, and outside judges and "gatekeepers" assessing and reacting to an innovation, on the other hand.

Phase $\mathrm{I}$ is a sub-context in which actors experience challenges, curiosity, expressive needs, social, political, economic and technical pressures, etc. (motives for initiating an innovation process and developing it is often mixed). There is a social organizational context whether a network, group, large-scale organization, or other collective arrangement.

In the innovation process, an agent or agents try to frame and define the challenge or problem and its dimensions in Phase II. In the course of determining what is the challenge or problem, how it should be conceptualized, the agent or agents try to mobilize resources (including possibly qualified people and problem-solvers) and operate/conduct one or more creativity production function leading to an output - which with some likelihood might be an innovation "solving" the initial challenge, problem, or need.

Many attempts at innovation fail because actors cannot mobilize critical resources in their social context, for instance, they lack ownership rights, authority or access to forms of "venture capital"; or, they lack technologies or socio-technical infrastructures like laboratories or particle accelerators; or, they lack sufficient relevant knowledge (or access to expertise with such knowledge; it might not be available in the setting, for instance, in a developing country without substantial modern educational infrastructure); or, in the case of a multiagent process, the actors lack organizational capability essential for mobilizing and coordinating/controlling the people and resources (the task-resource-agency nexus) and executing one or more creativity production functions. 
Table 4

Phase model of the generation and acceptance of innovations and creative developments

\author{
PHASE I Crucible of emerging demands, pressures, \\ challenges, opportunities, quandaries in a social \\ organizational context
}

PHASE II Framing and defining the challenge, problem, its dimensions in the organizational context

PHASE III Mobilizing and operating one or more creativity production functions in the social organizational context with self-confidence and capability

PHASE IV Creative agent or agents accepts/verifies the innovation as right and proper or Not in their social organizational context

PHASE V Social judgments and selection in the near context

PHASE VI \& VII Social judgment, acceptance, and institutionalization in the larger social organizational context
Initiating conditions and processes: Recognition of unfulfilled need by an initiating actor or group; opportunities to possibly solve a key problem, meeting an unfulfilled need, or opportunities to gain wealth $\&$ recognition. Actor(s) experience of a question, issue, gap; for instance, in context of mixing and movement of people (diversity of perspectives and experiences). Or, anticipation or experience of fun, imagination. For instance, actors in a community or network initiate an innovation processes; or, an Adm. Chief or leader in a group or organization initiates the problem-solving process in pursuit of particular group interests or goals.

In a given social organizational context, actors define (identify), constructing the problem and articulate possible strategies to solve, or solutions to try, identifying variants or prototypes

Individual or collective creative operations, mobilizing appropriate, available ideas, people, technologies and other resources if possible.

Creative activities: Origination/formation, adaptation Transformation and Dialectics.

- Operations of adjustment, re-arrangement, re-combination, substitution or replacement

-Trial and error and other forms of experimentation

- Recruit or have contact with person(s) with a different perspective (consultants, experts from other fields)

- Norms of alertness to chance discoveries or developments

- Activities of imagination and play

Judging \& testing on the part of the agent(s) directly involved in the creative actions and innovations - Critically assessing their" innovations", acting as their own gatekeepers or out of fear of gatekeepers (authorities, power brokers) in the larger context

Selection or Rejection of the innovation by gatekeepers in the immediate context (network, larger group or organization)

Socio-political Judgment and incorporation of innovation beyond the immediate innovating agent, group, or institution - or NOT (that is blockage or suppression). Even after possible acceptance/ institutionalization, an innovation may be rejected if it does not provide satisfactory enough solutions to relevant problem(s), or produces excessive unintended negative consequences; results that cannot be corrected or only corrected at un-sustainable expense, or faces major ideological opposition (e.g., nuclear energy or GMOs) (see these and other examples presented in Part II)

This made the group highly effective as a creative instrument but did not solve the challenges of acceptance and institutionalization by the overall organization (as in the case of Xerox, discussed in Part II).

(iii) The rule regime base (social relational and institutional arrangements) may vary in the different phases - indicated by differentiated norms, roles, and communication and collaboration is a critical factor $[23,32]$. As pointed out in Part II in the case of the PARC (at Xerox) group which created the PC, norms of sharing data and knowledge were established; openness in exchanges in their meetings was made standard practice, that is, one of several operative norms for the group. 


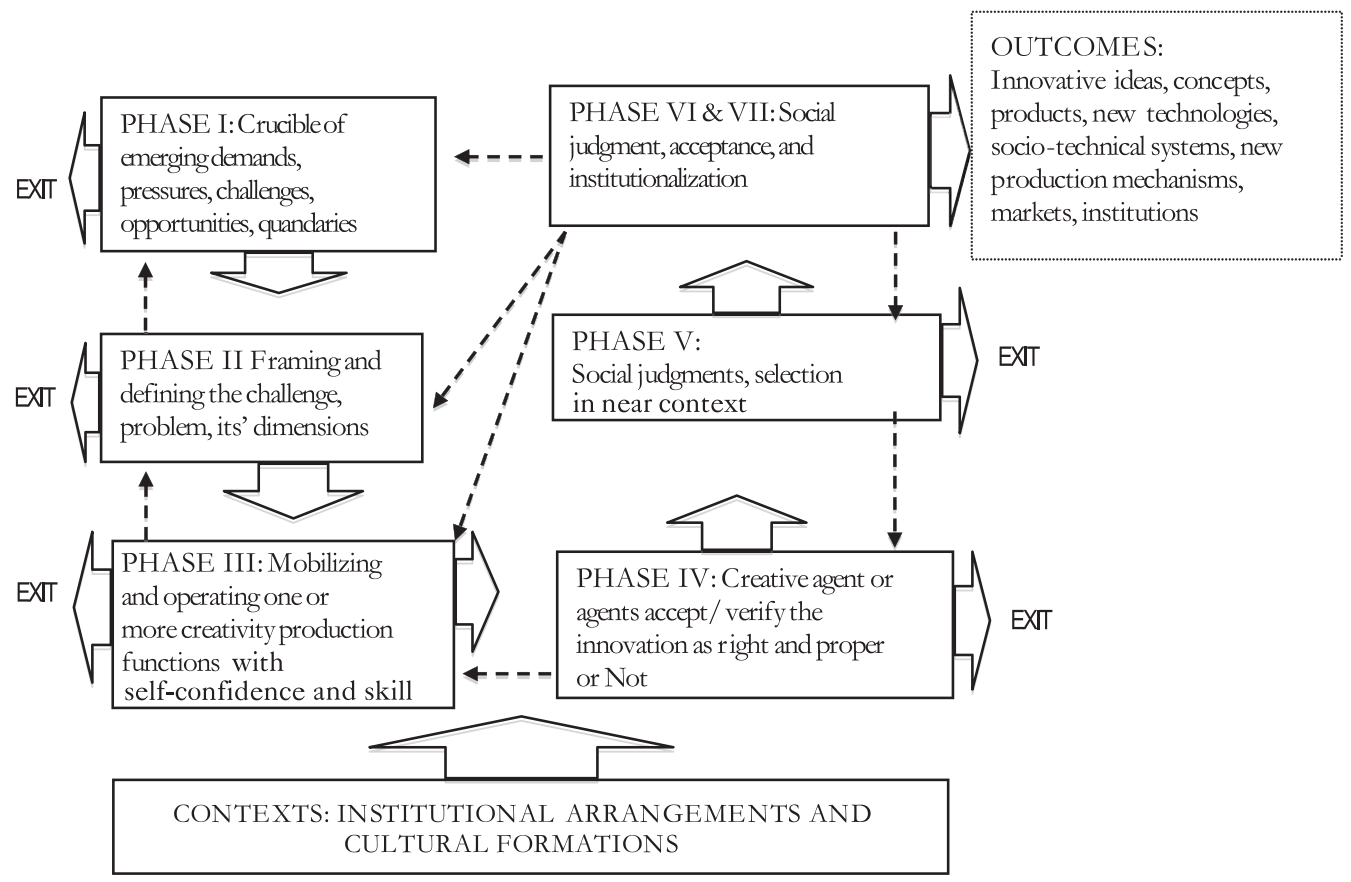

Fig. 2. Phase model of the generation and acceptance of innovations and creative developments.

leadership. For instance, ownership or property rights patterns are likely to shift. Ownership initially may be de facto. The group "owns" the innovation by virtue of immediate control or their isolation from external agents. "We can perform it, build it, execute it, others cannot, we therefore own it." Later ownership is institutionalized through patenting or copyrighting in the course of Phases IV, V, VI, \& VII (in which, of course, the innovators might not gain full control unless they are powerful companies or government agencies).

(iv) Few technologies and materials mobilized in the different phases typically vary. These differences are often qualitative but there may be quantitative differences, for instance, a shift from a need for a few limited resources and participants to massive mobilization, as production activities are moved from "a small garage" in which a prototype or a few variants are produced to substantial buildings where mass production is launched. Or a small group, through publications and educational programs, diffuses a new theory or model such as the DNA model into a vast network of knowledgeable professionals and developers.

(v) Note that access to or control over agents, technologies, materials, and the innovations themselves are mediated by the particular rule regimes (specifically, authority and ownership relations) which apply in one or more phases. (vi) Essential materials and technologies may be available to varying degrees to the agent or agents involved. A powerful agent has, or is likely to have, greater access to such resources than marginal or resource poor agents. Thus, even highly creative persons or groups may not be in a position to try or to realize their creations. The process of innovation cannot be initiated or completed. For instance, in the case of Leonardo da Vinci's many designs and inventions, there was a lack not only of sufficient knowledge but suitable resources and technologies for their realization. The realization of many of them had to wait several hundred years.

(vii) The interactions and production processes - and the leadership and division of labor - in the different phases usually differ substantially, particularly when multiple agents are involved (but in any case they may overlap to varying degrees).

(viii) In complex innovation developments, or in instances of cascading developments, the phase cycle is repeated numerous times, as strings and complexes of innovations are produced (see Part II about genetic engineering (GMOs) and nano-materials).

The phase model distinguishes the socio-cultural and institutional conditioning of creative activities ("the context of creativity, invention or discovery") from the acceptance/receptivity processes ("the context of 
acceptance and institutionalization"). The model orients us to looking for shifts in agents or their roles including leadership, in the interaction and production patterns, in the resources mobilized and deployed, and in the social relationships and interactions with agents outside of or not directly involved in the creative process per se. Also, a distinction is made between immediate or near reactions of acceptance or rejection (in Phases IV and $\mathrm{V}$ ) from those reactions in more encompassing contexts (typically economic and/or political) that enable or block acceptance and institutionalization (Phases VI and VII) (See Table 4 and Figure 2).

\section{Conclusions}

(1) Creativity and innovation are universal human activities, essential to adaptation and sustainability in an evolutionary perspective [13, 14].

(2) Creativity - in its production as well as acceptance - is socially embedded. Social structural factors - for instance, institutions, cultural formations, networks and groups of agents - operate in and through the phases of creativity, possibly facilitating creative action and innovation, on the one hand, or, constraining or blocking it, on the other hand. In other words, our theoretical and empirical research views the generation of novelty as a function of social structures (interaction fields, networks, groups, organizations), resource bases (appropriate materials and technologies), knowledgeable, capable, and selfconfident agents (individuals and collectives), and interaction processes (powering, exchanging, competing, and conflicting).

(3) Creativity and innovation studies, therefore, should systematically take into account the sociability, resources and powers of potential and participating agents, the institutional arrangements and cultural formations which make up, for instance, the context of invention and creativity as well as the context of acceptance and institutionalization, the two major contexts differentiated in our systems analysis (and taken up and illustrated in Parts II and III, respectively).

The approach distinguishes in Part II a number of different social organizational contexts of creativity, which opens the way to apply group [25, 32] and organizational theories $[7,15,23,74]$ as well as social network $[24,54]$ and societal transition theories $[13,14,20]$ to the description and analysis of creative activity in different contexts.

In Part III we analyze the context of receptivity, selection, and institutionalization of innovations and creative developments and suggest the likelihood that innovations are successfully introduced and institutionalized.

\section{Acknowledgments}

We are grateful to earlier collaboration with Tom Baumgartner, Marcus Carson, Philippe DeVille, Jerry Ellig, Peter Hall, Ilan Kelman, and Alison Woodward who have played a significant role in the development of the work presented here.

\section{References}

[1] T. Amabile, Creativity in Context: Update to the Social Psychology of Creativity Boulder, Colorado: Westview Press, 1996.

[2] T. Amabile, The Social Psychology of Creativity, New York: Springer-Verlag, 1983.

[3] WB. Arthur, The Nature of Technology, New York: Free Press, 2009.

[4] M. Batey and A. Furham, Creativity, intelligence, and personality: A critical review of the scattered literature, Genetic, Social, and General Psychology Monographs 132(4) (2006), 355-429.

[5] T. Baumgartner and T.R. Burns, Transitions to Alternative Energy Systems: Entrepreneurs, Strategies, and Social Change. Colorado: Westview Press, 1984.

[6] H. Becker, Art Worlds Berkerly: University of California Press, 1982.

[7] W.G. Bennis and P. Ward Biederman, Organizing Genius: The Secrets of Creative Collaboration. Basic Books, 1997.

[8] M.A. Boden, editor. Dimensions of Creativity. Cambridge, Mass: MIT Press, 1994.

[9] W. Buckley, Sociology and modern systems theory. Oxford, England: Prentice-Hall, 1967.

[10] W. Buckley, Society - A Complex Adaptive System: Essays in Social Theory. Amsterdam: Gordon and Breach, 1998.

[11] T.R. Burns, T. Baumgartner and P. DeVille, Man, Decisions, and Society. London: Gordon and Breach, 1985.

[12] T.R. Burns, U. Corte and N. Machado, Toward a Universal Theory of the Human Group: Sociological Systems Framework Applied to the Comparative Analysis of Groups and Organizations. ULI/CIES Report No 191/2014 Lisbon: University of Lisbon Institute/CIES; 2014. http://www.cies.iscte.pt/np4/ ?newsId=453\&fileName=CIES_WP191_Burns_Machado_Cor te.pdf

[13] T.R. Burns and T. Dietz, Cultural evolution: Social rule systems, Selection, and Human Agency International Sociology (7) (1992), 259-283.

[14] T.R. Burns and T. Dietz, Revolution: An evolutionary perspective, International Sociology 16(4) (2001), 531-555. 
[15] T.R. Burns and H. Flam, The Shaping of Social Organization: Social Rule System Theory with Applications London: Sage, 1987.

[16] T.R. Burns and A. Gomolińska, Modeling Social Game Systems by Rule Complexes. In: Polkowski L, Skowron A, editors. Rough Sets and Current Trends in Computing Berlin/Heidelberg, Springer-V, 1998.

[17] T.R. Burns, Social Sciences and Technological Change. Brussels: EU Commission, Social Science and Humanities Advisory Group, Background Paper 2005 (BP6) (20050816).

[18] T.R. Burns, System Theories. In: The Encyclopedia of Sociology, Blackwell Publishing, Malden, Mass, 2006a.

[19] T.R. Burns, The sociology of complex systems: An overview of actor-systems-dynamics, World Futures: The Journal of General Evolution 62 (2006b), 411-460.

[20] T.R. Burns and P. Hall, editors. The Meta-Power Paradigm Impacts and Transformations of Agents, Institutions, and Social Systems. Capitalism, State, and Democracy in a Global Context. Peter-Lang publishing, 2012.

[21] T.R. Burns and E. Roszkowska, The social theory of choice: From simon and kahneman-tversky to GGT modeling of socially contextualized decision situations, Optimum- Studia Ekonomiczne 3(39) (2008).

[22] M. Carson, T.R. Burns and D. Gomez Calvo, Public Policy Paradigms: Theory and Practice of Paradigm Shifts in the European Union. Peter Lang, Frankfurt/New York/Oxford, 2009.

[23] K. Chen, Organizing creativity: Enabling creative output, process, and organizing practices, Sociology Compass $6(8)$ (2012), 624-643.

[24] R. Collins, The Sociology of Philosophies: A Global Theory of Intellectual Change Harvard University Press, 2000.

[25] U. Corte, A refinement of collaborative circles theory: Resource mobilization and innovation in an emerging sport, Social Psychology Quarterly 76(1) (2013), 25-51.

[26] M. Csikszentmihalyi, Creativity and Genius: A systems perspective In: Steptoe A. Genius and the Mind. Oxford: Oxford University Press, 1998:39-66.

[27] M. Csikszentmihalyi, Creativity: Flow and the Psychology of Discovery and Invention. New York: Harper Perennial, 1996.

[28] M. Csikszentmihalyi, Implications of a Systems Perspective for the Study of Creativity. In: Sternberg RJ, editor. Handbook of Creativity. Cambridge, England: Cambridge University Press, 1999, pp. 313-38.

[29] M. Csikszentmihalyi, Society, culture, and person A system view of creativity. In: R.J. Sternberg. The nature of creativity. New York: Cambridge University Press, 1988, pp. 325-339.

[30] M. Csikszentmihalyi, Society, Culture, And Person: Creativity. In: R.J. Sternberg, editor. Cambridge: Cambridge University Press, 1990

[31] M. Csikszentmihalyi, The domain of creativity In: Runco MA, Albert RS, editors. Theories of creativity. Newbury Park, CA: Sage, 1990, p. 212.

[32] M.P. Farrell, Collaborative Circles: Friendship Dynamics and Creative Work. University of Chicago Press, 2001.

[33] S. Firestein, What scientists really do? New York Review of Books 2014, October 23.

[34] R.L. Florida, The Rise of the Creative Class: And How It's Transforming Work, Leisure, Community and Everyday Life. Basic Books, 2002.
[35] S. Gautam, The Four P's of Creativity Ms, 2012.

[36] A. Giddens, The Constitution of Society Oxford: Polity Press, 1984.

[37] C. Gilfillan, The Sociology of Invention. Follett Publishing Co, Chicago, 1935.

[38] C. Gilfillan, The sociology of invention: An essay in the social causes, ways, and effects of technic invention, especially as demonstrated historically [sic] in the author's Inventing the ship. Cambridge, Mass.: MIT Press, 1970.

[39] E. Goffman, Frame Analysis: An Essay on the Organization of Experience. Cambridge, Mass: Harvard University Press, 1974.

[40] E. Gorny, editor. Dictionary of Creativity: Terms, Concepts, Theories \& Findings in Creativity Research. Netslova, Russia; 2007. http://creativitynetslovaru/Memehtml.

[41] M. Granovetter, Economic action and social structure: The problem of embeddedness, American Journal of Sociology 91 (1985), 481-510.

[42] R. Harre and P.F. Secord, The Explanation of Social Behavior. Oxford: Blackwell, 1972.

[43] R. Hollingsworth, et al. Major discoveries, creativity and dynamics of science. Edition Echoraum, Vienna, 2011.

[44] H. Joas, The Creativity of Action. University of Chicago Press, 1996.

[45] J. Kaufmann and R.J. Sternberg, editors. The Cambridge Handbook of Creativity. New York: Cambridge University Press, 2010, pp. 145-173.

[46] J. Kemeny, Professional ideologies and organizational structure: Tanks and the military, European Journal of Sociology 24 (1983), 223-240.

[47] D. Kevles, The Genes You Can't Patent. NYRB 2013, September 26.

[48] T.I. Lubart, Componential Models In: MA Runco; S Pritzer, editors. Encyclopedia of Creativity, New York: Academic Press, 1999.

[49] N. Luhmann, Social Systems. Stanford, Calif: Stanford University Press, 1995.

[50] D.W. MacKinnon, Creativity: A multi-faceted phenomenon. In: J Roslanksy, editor. Creativity. Amsterdam: North-Holland Publishing, 1970.

[51] P. McIntyre, The systems model of creativity: Analyzing the distribution of power in the studio, Journal on the Art of Record Production (2008).

[52] A. Montuori, Creativity: Systems Approach. In: Runco and Pritzer (eds).

[53] W.F. Ogburn, Social Change. New York: Dell, 1922.

[54] J.F. Padgett and W.W. Powell, The Emergence of Organizations and Markets. Princeton (NJ), Princeton University Press, 2012.

[55] J.N. Parker and E. Hackett, Hot spots and hot moments in scientific collaborations and social movements, American Sociological Review 77(1) (2012), 21.

[56] T. Parsons, The Social System. Glencoe, IL: Free Press, 1951.

[57] G.J. Puccio and J.F. Cabra, Organizational creativity: A systems perspective. In: Kaufmann J, Sternberg RJ, editors. The Cambridge Handbook of Creativity. New York: Cambridge University Press, 2010, pp. 145-173. 
[58] M. Rhodes, An analysis of creativity the phi delta kappan, 42(7) (1961), 305-310.

[59] C. Riggs, Bull with wings. Review of D Wengrow's The Origins of Monsters. TLS 2014, September 12, p. 25.

[60] E. Roszkowska and T.R. Burns, Fuzzy bargaining games: Conditions of agreement, satisfaction, and equilibrium, Group Decision and Negotiation 19(5) (2010), 421-440.

[61] M.A. Runco and S. Pritzer, editors. Encyclopedia of Creativity. 2nd edition. New York: Academic Press year.

[62] R.K. Sawyer, Explaining Creativity: The Science of Human Innovation. Oxford University Press, 2012.

[63] R.K. Sawyer, Group Creativity: Music, Theater, Collaboration. Psychology Press, 2003.

[64] R.K. Sawyer, Group Genius: The Creative Power of Collaboration. Basic Books, 2008.

[65] D.K. Simonton, Creativity in Science: Chance, Logic, Genius, and Zeitgeist. Cambridge University Press, 2004.

[66] D.K. Simonton, Origins of Genius: Darwinian Perspectives on Creativity. Oxford University Press, 1999.

[67] R.J. Sterling, Handbook of Creativity. Cambridge: Cambridge University Press, 1998.

[68] A. Swidler, Culture in action: Symbols and strategies, American Sociological Review 51(2) (1986), 273-286.
[69] A. Tversky and D. Kahneman, Judgment under uncertainty: Heuristics and biases, Science 185 (1974), 1124-1131.

[70] I. Wallerstein, World-Systems Analysis: An Introduction. Durham, NC: Duke University Press, 2004.

[71] R.W. Weisberg, Creativity: Understanding Innovation in Problem Solving, Science, Invention, and the Arts. Hoboken, N.J.: John Wiley \& Sons, 2006.

[72] D. Wengrow, The Origins of Monsters. Princeton: Princeton University Press, 2014.

[73] R.W. Woodman, J.E. Sawyer and R.W. Griffin, Toward a theory of organizational creativity, The Academy of Management Review 18(2-Apr) (1993), 293-3.

[74] A.E. Woodward, J. Ellig and T.R. Burns, Municipal Entrepreneurship and Energy Policy: A Five Nation Study of Politics, Innovation, and Social Change. New York: Gordon and Breach, 1994.

[75] M. Zeleny, Autopoiesis: A Theory of Living Organization. New York: North-Holland, 1981.

[76] M. Zeleny, Autopoiesis (self-production) in SME networks, Human Systems Management 20 (2001), 201-207. 